Teachers' perceptions of physical education in Aotearoa/New Zealand primary schools

\title{
ABSRACT
}

This study examines practicing primary school teacher's perceptions of the teaching of physical education in their schools. There has been some criticism of primary school physical education but until now this criticism has been largely based on a number of small studies involving limited numbers of teachers and schools. This study involved surveys of 487 teachers and in-depth individual interviews with 33 teachers located across six major regions of Aotearoa/New Zealand. The findings are presented in four themes: what does physical education look like; who teaches physical education; planning, assessment and reflection; and influences on the teaching of physical education. The study identified that what occurs in the physical education space in primary schools is often inconsistent and variable. The findings are discussed in relation to the requirements of the New Zealand Curriculum, the 2014 National Monitoring Study of Student Achievement report and previous research on primary school physical education. The article concludes by discussing future directions for the teaching physical education in light of these findings.

Keywords: physical education, primary school, external providers

This study examines the perceptions of practicing primary school teachers on the teaching of physical education in primary schools in Aotearoa/New Zealand. Physical education has been positioned as an integral part of the education experience for students in New Zealand over many years. In the present New Zealand Curriculum (NZC) (MOE, 2007) Health and Physical is designated as one of the eight key learning areas that are mandated to be taught in all schools. Physical education has a long history of modification over time and has been presented to teachers in various iterations, generally in response to political, societal and educational changes. From its initial role in physical training to prepare boys for possible military service, physical education has evolved slowly to become more scientifically focused with "the emphasis moving from external control of the body (and person) to individual accountability for health and fitness" (Culpan, 2004, p. 227). In recent times the influence of neoliberal discourses on physical education has been the subject of a great deal of discussion (MacDonald, Hay, \& Williams, 2008; Pope, 2014). These discussions have led to the identification of clear links between neoliberal discourses, policy changes and outcomes in school physical education (Pope, 2014). These outcomes have included changes in the preparation of teachers, a greater focus on measurable goals and increased outsourcing of health and physical education in schools.

A significant challenge for teachers has been incorporating the substantial changes that were made to the philosophical and conceptual framework underpinning the Health and Physical Education in the New Zealand Curriculum Statement (1999) and the New Zealand Curriculum (Ministry of Education, 2007), into their teaching practice. While movement is still central to the learning area "the focus is on movement and its contribution to the development of individuals and communities" (MOE, 2007, p. 23), the NZC also describes a wider view of physical educations contribution. This is clearly demonstrated in the health and physical education's essence statement which states that students should learn to "relate positively to 
others and demonstrate constructive attitudes and values ... it [health and physical education] fosters critical thinking and action and enables students to understand the role and significance of physical activity for individuals and society" (p. 23).

There has been some examination of primary school physical education and the degree to which the teaching and learning in this learning area is aligned with and achieving the potential of the NZC (Cosgriff et al., 2013; Gordon, Cowan, McKenzie, \& Dyson, 2013; Penny, Pope, lisahunter, Phillips, \& Dewar, 2013; Petrie, 2011; Smith \& Philpot, 2011). This body of research suggests that the degree to which the intent of the NZC is being met in schools is variable. A number of potential factors that may influence the content and quality of the teaching and learning have been identified. These include government policies around sport and obesity via Sport New Zealand, the government's concentration on numeracy and literacy and the resultant introduction of national standards (Paine, 2013). Other important factors include a decrease in time for pre-service teacher education, a reduction of advisory services, limited professional development opportunities and poor resourcing (Gordon, 2011; Gordon, et al., 2013; Paine, 2013; Petrie et al., 2013; Smith \& Philpot, 2011). One factor that has been consistently mentioned is the high volume of external providers (EPs) in the schools (Petrie, Penney, \& Fellows, 2014). This situation has received some critique including the resulting lack of a comprehensive coverage of the NZC (Petrie, et al., 2014) and the negative impact(s) on the professional confidence of classroom teachers to teach physical education (Dyson, Gordon, Cowan, \& McKenzie, in press; Powell, 2015).

While acknowledging the potential impact of these influences, it is important to identify the (non)effectiveness of the teaching and learning that is occurring. One form of evaluation in physical education is the National Monitoring Study of Student Achievement (NMSSA) - Wānangatia Te Putanga Tauira (N. Z. Ministry of Education, 2014). This project evaluates student achievement across health and physical education at Year 4 and Year 8 in all New Zealand's English-medium state schools every five years. This evaluation is important in that it offers an evidencebased view of the outcomes that are occurring within the health and physical education learning area.

The latest NMSSA evaluation (N. Z. Ministry of Education, 2014) offered both positive and negative evidence for the learning that is occurring in physical education. Student movement skills were reported to have developed considerably from Year 4 to Year 8, although long-term gender and decile (socio-economic) differences identified in previous reports have been maintained. Of some concern was students' ability to meet the expected requirements of the NZC at their year level. The report described a dramatic drop off in the percentages of students able to meet the expected achievement standards in physical education from level two to four. ... "over 95 percent of students were achieving at Level 2 of the NZC ... by year 8 only 50 percent of students were achieving at Level 4 of the curriculum" (p. 7). These results suggest that there is a substantial problem with the learning in primary school physical education between year 4 and year 8 .

While previous research has offered an insight into primary school physical education these studies have generally been limited to small clusters of schools and /or teachers. Penney, et al (2013) examination of physical education and sport in primary schools was, for example, restricted to six schools while Penny, Petrie \& Fellows (2015), study looking at "the public and privately funded initiatives, programmes and resources targeted towards the provision of HPE" (p. 42) was limited to an analysis of what was available on the internet. 
What has been missing to date is a wide-ranging examination that included large numbers of teachers from major regions throughout Aotearoa/New Zealand. This wider examination is important as it will test the veracity of commonly held beliefs about primary school physical education, beliefs that are, through necessity, based on limited evidence, conjecture and personal experience. This is particularly important at this time as primary school physical education in Aotearoa/New Zealand faces substantial challenges to how and what is taught in schools. One recent example is the introduction of "Play.sport" an \$8 million Sport NZ initiative to be piloted in 34 primary schools. Sport New Zealand describes the initiative as aimed at "ensuring young people are getting quality PE and sport at school". The initiative has been largely driven by Sport NZ beliefs around inadequacies in primary school physical education and will include "practical support and training for teachers" (Sport New Zealand, 2016).

This study was designed to gain this wider view by examining teacher's perceptions of contemporary practice. It does so by exploring how physical education "looks" through the eyes of a substantial number of classroom teachers engaged in the teaching of physical education. The number of surveys (487) and associated interviews (33) across six major regions across Aotearoa/New Zealand provides us with the largest and broadest study to date. By seeking input from across all of these regions the study offers the perspectives of teachers who have been largely missed to date.

\section{Method and analysis}

This research incorporated a mixed methods approach (Greene, 2007) which allowed for quantitative and qualitative data to be integrated pragmatically throughout the data collection, data analysis and interpretation phases of the research (Creswell \& Plano Clark, 2011; Lincoln \& Guba, 1985).

A 32-item questionnaire was completed by 487 classroom teachers from 133 schools across six regions (Northland, Auckland, Wellington, Canterbury, Otago and Southland) in Aotearoa/New Zealand. The questionnaire contained 26 questions presented as a six point Likert Scale. Question 20, for example, asked teachers to respond to the statement that in their school "PE programmes are based on students learning needs". Potential responses ranged from Strongly Disagree to Strongly Agree. This data was analysed using SPSS software to generate descriptive statistics (Creswell \& Plano Clark, 2011; Greene, 2007). The questionnaire also contained six open questions, for example, "Please describe your current school PE context by indicating who is responsible for the delivery of PE programmes".

Following the survey 33 classroom teachers, who had indicated on their questionnaire they were willing to be interviewed, completed semi-structured interviews that lasted between 45-65 minutes. The interviews were guided by initial questions and follow up probes designed to elicit deeper responses from the teachers. One question, for example, followed up the more general questions around planning in the questionnaire by asking the teachers specifically "How much time do you spend planning for physical education on a weekly basis? Probe - How does this compare to planning time for subjects such as mathematics and literacy"? All interviews were transcribed verbatim by an independent graduate student and then entered into NVivo 9 software to aid the analysis of the data. A combination of inductive and deductive analysis was carried out (Greene, 2007). The initial coding was completed using a combination of pre-determined categories developed from the literature and categories that were identified during the analysis process. One researcher completed 
this initial coding and the coding was then peer reviewed by three other researchers.

Ethical approval for this study was received from the University of Auckland Human Participants Ethics Committee.

\section{Findings}

The findings are presented in four major categories identified from the data: What does physical education look like; Who teaches physical education; Planning, assessment and reflection; and Influences on the teaching of physical education.

\section{What does physical education look like?}

When asked to describe a "typical physical education lesson" the majority (22/33) of the teachers interviewed described some variety of the traditional approach to teaching physical education involving a teacher-directed lesson:

For me a typical lesson would start with a warm-up, it would be looking at what skill we are going to look at today. I would be demonstrating and then going away in pairs to do some ... Then we will apply them to a game (male teacher, mid-career).

This approach has been described by Hoffman (1971) as the demonstration, explanation and practice method and more recently Metzler (2000) and Kirk (2010) as "the physical education method". They describe a teacher-centred approach to teaching physical education in which students have a limited role in how the class operates. This pedagogical approach owes much to physical education's militaristic roots and offers comfort for teachers concerned with managing students outside the confines of the classroom. It is, however, philosophically at odds with the orientation of the New Zealand Curriculum, which places emphasis on creating a supportive learning environment, encouraging reflective though and action, facilitating shared learning and teaching as inquiry.

There have been a number of instructional models introduced into the practice of physical education that are more closely aligned with the NZC. Two of these Teaching Games for Understanding (TGfU) and Cooperative Learning were specifically mentioned during the interviews. Five teachers discussed TGFU or described a process based around game play and the developing of tactics that was similar to this approach:

Our current curriculum has a TGfU kind of base plan so we were working on the idea of invasion games in term 1 and term 2 that sort of thing (male teacher, experienced).

Ten other teachers mentioned TGfU but were not sure if they were doing it correctly or did not use it in practice:

We have heard about TGfU. And there was that [name] guy. So we have heard about them but we haven't used them (male teacher, mid-career).

Six teachers mentioned that Cooperative Learning was implemented in their physical education programmes. For the majority this was as a result of specific professional development they were receiving in this approach. A number of teachers 
focused on the intended outcomes in a broader sense mentioning activities such as fitness, aquatic skills, fundamental movement skills, and the development of social skills as being typical of physical education.

Teachers were also asked to identify what topics were taught. They reported a wide range including dance, a variety of sports and a range of activities loosely classed as fitness. Also mentioned were adventure based learning, perceptual motor programmes, Jump Jam and large and small ball skills. Education Outside the Classroom was also identified by 17 of the teachers interviewed as being an integral part of their programme:

Every year level is involved in outdoor education every year. Like orienteering, water wise, beach and bush days (female teacher, early-career).

\section{Who teaches physical education?}

There has been some discussion in the literature about who is actually in front of the students teaching physical education (Penny, et al., 2013; Petrie, et al., 2014). Traditionally the classroom teacher was responsible for their own class's physical education and was required to do the majority of the teaching. In recent years there has been a rapid increase in the numbers of EPs offering to teach physical education in primary schools. Pope (2014), in his article on the impact of neoliberalism on health and physical education, described the situation as "the marked appearance of agencies and organizations that have assumed a right to deliver parts of the curriculum and co-curriculum within many schools" (p. 500). This increase is largely the result of government policies, including the introduction of Kiwisport funding. Kiwisport allocates $\$ 13$ per student (\$6 million) per year to schools, an amount further supplemented by indirect funding through 17 Regional Sports Trusts. This funding is intended to promote and establish partnerships between community groups, schools, clubs and other sporting providers (Dyson, et al., in press).

The questionnaire confirmed that EPs have a strong presence within New Zealand primary school physical education identifying 638 providers active within the 113 schools (Table one). The teachers interviewed identified that the teaching of the physical education curriculum in their classrooms was shared between themselves and EPs. The relationship between the teachers and EPs varied with some teachers working alongside the EPs teaching lessons in support of their work. Others tended to simply abdicate their responsibility to teach physical education to the EPs. One teacher observed:

We do [teach physical education], I think individual teachers do. However in saying that a lot of experts do come and help and I think there is quite a lot of teachers who rely on that to happen and that would probably be their PE (female teacher, experienced).

The teachers looked to the EPs as a source of expertise that they didn't possess themselves and in some cases as providers of professional development (PD) in physical education:

Teachers are willing to take them on board [EPs] because their learning something from them as well and can feed off them (male teacher, mid-career).

This is consistent with the NMSSA report (N. Z. Ministry of Education, 2014) 
which reported that $80 \%$ of teachers stated they had received PD in health and physical education within the last two years and that EPs were the main source of this PD.

Table 1. Types and number of external providers in schools

\begin{tabular}{|l|l|}
\hline Categories & Numbers \\
\hline Sports Codes & 56 \\
\hline Organisations & 179 approx \\
\hline Unnamed Instructors/Organisations & 366 \\
\hline Regional Sports Trusts & 15 \\
\hline Other Trusts & 4 \\
\hline Public Facilities (not linked to an organisation) & 4 \\
\hline Personal & 9 \\
\hline Specialist PE Teachers & 1 \\
\hline
\end{tabular}

While EPs were seen as "experts" the teachers had mixed feelings about the quality of their work. They described a number of externally provided programmes as high quality, including EOTC, aquatics and some sports foundation and commercial programmes. There was criticism, however, about the pedagogical approaches used by many of the EPs and the lack of alignment of their programmes [whether it was the EPs responsibility or not] with the NZC. In an attempt to gain a sense of how the EPs work was monitored the teachers were asked about student assessment and program evaluation. The most common response was simply that no assessment or evaluation occurred.

They are not as far as I know [evaluated]. I presume that they may send out an evaluation form at the end of the 10 sessions but certainly as a teacher I'm not asked to evaluate them (female teacher, early-career).

In many instances teachers were not able to identify by name the EPs who were teaching their students, and in these cases a professional relationship where both parties worked together to meet the needs of students seems unlikely.

In relation to their own role in teaching physical education the majority of teachers described themselves as generalist teachers who taught PE as part of their professional practice. Some described themselves as specialist PE teachers due to their knowledge and interest and were recognized by the school as, for example, the Sport's Coordinator. Their major responsibility was organizing school sport along with physical education responsibilities such as developing programmes and organizing EPs. 


\section{Planning, assessment and reflection}

The study was interested in understanding how teachers planned, assessed and reflected on their teaching of physical education. These processes are central to the teaching and learning that occurs for both the teacher and the students and are indicative of the teacher's commitment to physical education as an educative context. In relation to full school planning 365 (75\%) of teachers surveyed agreed or strongly agreed that in their school "teaching programmes are developed from an overall school policy" while $330(68 \%)$ agreed or strongly agreed "the school allocates curriculum time to PE."

When it came to individual lesson planning the results were less positive. Only $190(39 \%)$ of the teachers surveyed agreed or strongly agreed "Planning meets the needs of the Health and PE statement" (p. 22, MOE, 2007). The interviews also painted a clear picture of teachers spending little time planning for their physical education lessons. Of those interviewed four reported spending between 20 and 30 minutes planning physical education per week while three spent more than 30 minutes. For the remainder planning either did not occur or was extremely limited:

Sometimes I do lesson plans, well, I just get a whole bunch of activities and put them together and work through them (female, beginning teacher).

While the teachers did little planning for physical education, this did not reflect a reluctance to plan. Teachers often reported spending large amounts of time planning in other learning areas, in particular numeracy and literacy:

It wouldn't even factor it in [PE planning]. Literacy and maths would be above everything else because it's on national standards and it's seen as, well I say it's seen as important (female teacher, early-career).

These comments show that teachers value planning, and see it as important in helping generate quality teaching and learning in high status subjects. Their decision to negate planning in physical education is a strong message that quality teaching and learning in this learning area is seen as less important.

Assessment is another important element in quality teaching and learning "as both student and teacher respond to the information that it provides" (NZC, P. 39). A series of questions sought to establish what assessment looked like in practice. While teachers are encouraged to use a variety of modes of assessment this was not the case in this study. Three hundred and thirty teachers (68\%) either disagreed or only agreed slightly with the statement "a range of assessment strategies are used to assess students". This view was supported by the interview data where an informal process of teacher observation with no teacher assessment recorded or reported predominated (28/33). On the question of student involvement there was contradictory data. While the teachers interviewed reported that students used peer-assessment (14) and selfassessment (19) in the questionnaire only 165 (34\%) agreed or strongly agreed with the statement "students are actively involved in the evaluation process". Of some concern was that only 241 teachers (49\%) agreed with the statement "judgments were regularly made about what students know and can do in relation to the PE syllabus outcomes".

When exploring potential barriers to assessment in physical education the number one barrier identified was lack of time. This referred to both lack of time for physical education and lack of time during individual lessons. Other barriers 
identified were a lack of physical education knowledge (9) and the problem of assessing movement (4):

The possible barrier is that PE assessment happens there and now, whereas with a writing assessment I can take that home with me on the weekend and do it then and refer to it anytime (female, beginning teacher).

The role that reflection played in the teaching of physical education was also considered. A large majority of those interviewed (27) reported that they reflected on their teaching and for many it was a part of their normal practice. Reflections were most commonly around whether the students were enjoying the lesson, identifying what went well and what they would change next time. A small number (6) specifically identified reflecting on the degree to which students were successfully learning skills:

I am doing it all the time. Absolutely...Reflecting at the end of the lesson coming up to the next one, what do we change (female teacher, mid-career).

In general teachers reported that they valued the process of reflection as a means to improving the teaching and learning that occurred in physical education. Only a small minority (4) made little or no attempt to reflect on their physical education lessons:

I guess I must do, but I mean I know what I like to do, so I sort of ... I try to make it fun and I try to make it easy ... yeah so I probably don't reflect as much as I should (female teacher, mid-career).

\section{Influences on the teaching of physical education}

All schools and teachers are influenced by the social and cultural context in which they are situated. These influences impact on the school at a multitude of levels from school wide policy to the day-to-day practices of the individual teacher. This study was therefore interested in exploring the teacher's views on the factors, both in and out of school, they saw as having an impact on their teaching of physical education.

In discussing major influences sixteen of the teachers interviewed made specific reference to the negative impact the emphasis on numeracy and literacy and/or the introduction of National Standards was having on the teaching of physical education:

And teachers are like "my goodness I have to get reading and writing done because its national standards" all the information, data is going up there so off PE goes cause I have run out of time (female teacher, early-career).

While feeling pressures from within the school around numeracy and literacy they also reported feeling similar pressures from parents and the wider society:

All you hear on TV is the Minister of Education talking about five out of five in numeracy and literacy, blah blah blah and I get up and remind parents that actually there are seven (sic) curriculum areas and we are there to give a balanced and rich curriculum (male teacher, mid-career). 
Other strong influences within the school context were the availability of facilities and resources. In relation to facilities there appeared to be a large disparity between schools. Around half of the teachers described the availability positively while the rest identified problems. These problems were predominately around a lack of adequate indoor space, a problem exacerbated by multiple uses of the school halls and the impact of poor weather. One teacher with over 40 years of teaching expressed her frustration:

And if it rains, well there goes PE. We are a huge school and we only have hall space inside if it's raining, which is often already booked (female teacher, experienced).

Contrary to a commonly held belief in the Physical Education profession, the teachers interviewed were generally very positive about the resources. Most felt well supported by the school and in many cases fundraising from the Parent Teachers Association or similar bodies were mentioned. A small group were less enthused describing their resources as just adequate or in three cases poor.

Most teachers felt that their administration and leadership teams were supportive of physical education although a small number felt that there was little commitment to the learning area in their schools or that it was not valued by their wider community:

It is generally valued but we are not going to make a big fuss about it when there are other things going on. And that is also going from the feel of the community. They are not going to say how is my child going in PE, but they will say how well is my child going with reading? So I think definitely they care more about your more academic things (male, early-career).

\section{Discussion}

This study examined teacher's perceptions of the teaching of physical education in primary schools in Aotearoa/New Zealand. It identified that what occurs in the physical education space within Aotearoa/New Zealand primary schools is often inconsistent and variable. While some programmes appeared challenging and educationally sound others were less so, in both the content delivered and in the ways that physical education was taught. It is important to acknowledge that quality teaching and learning is occurring in some primary school physical education. The presence of pedagogical models, such as TGfU and Cooperative Learning and student involvement in self and peer-assessment are all indications that some teachers have moved away from the more traditional approaches. The adequacy of resources is another positive although there is some need for further examination to ensure the resources are sufficient for quality physical education and not simply adequate for truncated sports and fitness programmes.

Typically there appeared to be a good support for the presence of physical education in primary schools. While teachers generally reported that physical education was valued, a number of their practices would suggest that for many this was not their personal belief. The limited planning, assessment and critical reflection on physical education, when compared to numeracy and literacy, demonstrates that many teachers felt that teaching and learning in physical education was of less value than other subjects. This is a belief that appears to have been reinforced by the 
introduction of educational policies that focus on numeracy and literacy (Paine, 2013).

A number of studies have offered support for the value of quality physical education (Dollman, Boshoff , \& Dodd, 2006; Rasberry et al., 2011). Telford's (2013) work in Australia, for example, a four-year randomized cluster intervention study of 29 primary schools ( 853 children), found participants in quality physical education benefited physically and also did better in assessments of numeracy and literacy. That active students receiving a well-balanced curriculum are healthier and achieve better academically is no great surprise to physical educators. It appears, however, that this belief is not held by all, including those responsible for educational policy in New Zealand.

The prevalence of EPs has a substantial impact on the teaching and learning that occurs under the banner of physical education. While the EPs do work in out-of school contexts they are also involved in physical education curriculum delivery. Pope (2014), for example, described a recent report from Sport New Zealand that showed $44 \%$ of approved Kiwisport projects were delivered during curriculum time. While acknowledging that EPs were teaching in their class's physical education time, there was no attempt by teachers to evaluate the programmes or assess student learning. This is despite $76 \%$ believing that "programmes in PE are improved as a result of evaluation". This contradiction illustrates that for many teachers EPs taught programmes were seen as somehow separate from the educative process that schools are committed to. It is difficult not to read this, in combination with many teachers inability to recall who was taking their classes, as teachers taking the opportunity to "hand over" what for many is a challenging learning area in the curriculum.

The reality is that EPs are well established in schools and recent initiatives by Sport New Zealand suggest they will become even more prevalent. Grant (2014) asked the reasonable question "does it really matter if outside providers contribute to HPE programmes"? (p. 17). This research would suggest that it depends very much on what they are providing. If students are participating in non-evaluated programmes, presented without an alignment to the NZC (MOE, 2007) and taken by instructors that teachers don't know then, yes, it does matter. If, however, EPs offer high quality experiences integrated as part of students total learning, then that would potentially offer better value than would be provided by the classroom teacher. There is certainly potential for positive collaboration whereby the teacher's educational strengths and knowledge of the students can be supplemented by the specific content knowledge base of EPs.

Where disjointed and non-comprehensive physical education programmes are offered this is a major concern for the authors. As Petrie and lisahunter (2011) warned "principals and teachers need to be mindful of what they will give away in terms of curriculum ownership amidst moves towards further outsourcing” (p. 335).

A final implication of the presence of EPs is their potential to erode confidence and effectively disempower teachers around the teaching of physical education. That so many teachers looked to non-trained EPs, who may or may not have knowledge of the NZC (MOE, 2007), as physical education experts and as a source for professional development signals that this process has already occurred for many teachers.

\section{Conclusion}

While acknowledging that there are positive learning environments occurring in physical education this study raises a number of issues. Many of these issues are 
not new, a fact that of course does not negate their importance. Primary teachers are in a difficult position with a variety of, at times, conflicting pressures and in many cases limited ability and experience in the teaching of physical education. As Grant (2014) commented "it is unrealistic to expect 'miracles' from those [primary teachers] with much less knowledge, particularly if they lack the confidence and competence to teach the conglomerate of skills incorporated in HPE" (p. 18).

Kirk (2010) in his discussion on the future of physical education identified three possible outcomes "more of the same, radical reform and extinction ... with the first being judged most likely in the short to middle term and the last in the long term" (p. 138). This study offers support for the belief that if the neoliberal influence on initial teacher education, EPs and the predominance of numeracy and literacy continue then the third option, whereby physical education role as an educative context contributing to the holistic development of all students will effectively cease to exist, is the most likely future.

What then is the best way forward so that primary school physical education achieves the educative value intended by the NZC (MOE, 2007) and our children experience the quality physical education they deserve? An increased valuing of the educational knowledge and professionalism of the classroom teacher would be a positive start. Their knowledge of the NZC, and of the learners in their classrooms, is a crucial element in facilitating quality learning. Aligned with this is the need for quality teaching in physical education. As the NMSSA (2014) report commented, if students are to be successful they "need to have been exposed to specific health and physical education teaching" (p. 7).

At a personal level all of us can take every opportunity to challenge the present ideology that attempts to reduce education to numeracy and literacy. By becoming visible and vocal advocates for quality physical education we can help develop a greater understanding in our communities around the contributions the learning area can make to the holistic development of our children.

\section{References}

Cosgriff, M., Petrie, K., Keown, S., Devcich, J., Duggan, D., \& Naera, J. (2013). What's in a name? re-imagining health and physical education in the primary school. Journal of Physical Education New Zealand, 10-13.

Creswell, J., \& Plano Clark, V. (2011). Designing and Conducting Mixed Research. California: Sage.

Culpan, I. (2004). Physical education curriculum development: A humanistic positioning. In A.-M. O'Neill, J. Clark \& R. Openshaw (Eds.), Reshaping culture, knowledge and learning: Policy and content in the New Zealand curriculum framework. Palmerston North, New Zealand: Dunmore Press.

Dollman, J., Boshoff , K., \& Dodd, G. (2006). The relationship between curriculum time for physical education and literacy and numeracy standards in South Australian primary schools. European Physical Education Review, 12, 151163.

Dyson, B., Gordon, B., Cowan, J., \& McKenzie, A. (in press). External providers and their impact on Primary School Physical Education in Aotearoa/New Zealand. Asia-Pacific Journal of Health, Sport and Physical Education.

Gordon, B. (2011). Ma te huruhuru ka rere to manu. Journal of Physical Education New Zealand, 44(2), 4. 
Gordon, B., Cowan, J., McKenzie, A., \& Dyson, B. (2013). Primary school physical education: The voices of teachers. Journal of Physical Education New Zealand, 46(2), 9-12.

Grant, B. (2014). Point of view: A changing landscape for HPE in primary schools The Journal of Physical Education New Zealand, 47(3), 16-18.

Greene, J. (2007). Mixed Methods in Social Inquiry. San Francisco, CA: Joeey-Bass.

Hoffman, S., J. (1971). Traditional methodology: Prospects for change Quest, 15(1), 51-57. doi: 10.1080/00336297.1971.10519701

Kirk, D. (2010). Physical education futures. London Routledge.

Lincoln, Y. S., \& Guba, E. (1985) Naturalistic Inquiry. Newbury Park, CA: Sage.

MacDonald, D., Hay, P., \& Williams, B. (2008). Should you buy? Neo-Liberalism, neo-HPE, and your neo-job. Journal of Physical Education New Zealand, 41(3), 153-168.

Metzler, M. (2000). Instructual Models for Physical Education. Needham Heights, MA: Pearson Education.

Ministry of Education. (2007). The New Zealand Curriculum. Wellington: Learning Media.

Ministry of Education, N. Z. (1999). Health and Physical Education in the New Zealand Curriculum. Welllington: New Zealand.

Ministry of Education, N. Z. (2014). National monitoring study of student achievement: Health and physical education. Otago: New Zealand: New Zealand Council of Educational Research.

Paine, A. (2013). The effects of National Standards on the teaching of health and physical education in the New Zealand Curriculum. Masters of Education, University of Auckland.

Penny, D., Pope, C., lisahunter, Phillips, S., \& Dewar, P. (2013). Physical Education and Sport in Primary Schools. Hamilton: The University of Waikato.

Petrie, K. (2011). An enduring issue: Who should teach physical education in New Zealand primary schools? Journal of Physical Education New Zealand, 44(1), 12-17.

Petrie, K., Burrows, L., Cosgriff, M., Keown, S., Naera, J., Duggan, D., \& Devcich, J. (2013). Everybody Counts? Reimagining Health and Physical Education in Primary Schools. Hamilton: University of Waikato.

Petrie, K., \& lisahunter. (2011). Primary teachers, policy and physical education. European Physical Education Review, 17(3), 325-339.

Petrie, K., Penney, D., \& Fellows, S. (2014). Health and physical education in Aotearoa New Zealand: an open market and open doors? Asia-Pacific Journal of Health, Sport and Physical Education, 5(1), 19-38.

Pope, C. (2014). The jagged edge and the changing shape of health and physical education in Aotearoa/New Zealand. Physical Education and Sport Pedagogy, 19(5), 500-511.

Powell, D. (2015). Assembling the privatisation of physical education and the 'inexpert' teacher. Sport, Education and Society, 20(1), 73-88. doi: doi: 10.1080/13573322.2014.941796

Rasberry, C., Lee, S. M., Robin, L., Laris, B., Russell, L., Coyle, K., \& Nihiser, A. (2011). The association between school-based physical activity, including physical education, and academic performance: A systematic review of the literature. Preventive Medicine, 52, 10-20. doi:

10.1016/j.ypmed.2011.01.027 
Smith, W., \& Philpot, R. (2011). The preparation of HPE teachers in New Zealand. Asia-Pacific Journal of Health, Sport and Physical Education, 2(3/4).

Telford, D. (2013). Are our primary school graduates physically literate? Paper presented at the ACHPER, Melbourne: Australia. 